\title{
Aerodynamic Characterization of a Non-Lethal Finned Projectile at Low Subsonic Velocity
}

\author{
Véronique de Briey * \\ Royal Military Academy, Brussels, Belgium \\ Alexandre de la Filolie ${ }^{\dagger}$ \\ Ecole de l'Air, Salon-de-Provence, France \\ Benoit Marinus $\stackrel{\ddagger}{\sharp}$ \\ Royal Military Academy, Brussels, Belgium \\ Marc Pirlot ${ }^{\S}$ \\ Royal Military Academy, Brussels, Belgium
}

Extended abstract

\section{Nomenclature}

CFD $=$ Computational Fluid Dynamics
RBD $=$ Rigid Body Dynamics
RANS $=$ Reynolds Average Navier-Stokes
$C_{D}=$ Drag Coefficient
$C_{L}=$ Lift Coefficient
$C_{M}=$ Pitch Coefficient

\section{Introduction}

Nowadays, the trajectory model for a low subsonic fin-stabilized projectile at low angle of attack is typically a point-mass model [1], taking only gravity and a constant zero yaw drag coefficient into account. This choice can be qualitatively justified for applications with short ranges and/or limited calculation resources. The disadvantage of this approach is the lack of prediction on the precision and the attitude of the projectile when hitting the target, because of a possible instability in flight. However, the use of non-lethal or less-lethal projectiles requires that the impact conditions are met, otherwise more serious injuries may occur. Therefore, the consideration of all forces and moments acting on the projectile in flight is mandatory to predict static and dynamic stability [2-7], already in the body shape design as well as in the controller design process.

Until now, many efforts have been completed in steady and unsteady CFD methods to obtain a complete set of aerodynamic coefficients for gyroscopic and fin-stabilized projectiles in all flight regimes, from subsonic to supersonic speeds [8-13]. The first accurate results for fin-stabilized projectiles with relatively cost-effective steady-state methods were obtained in the supersonic regime, except for the pitch-damping coefficient who requires in some cases time-accurate solutions [14-19]. For the subsonic regimes, pure steady-state simulations showed less reliability in most of the configurations and the use of time-accurate techniques for all dynamic derivatives still seems unavoidable. When computing resources are available, the recent coupling between CFD and Rigid Body Dynamics (RBD) now makes it possible to calculate accurately both static and dynamic derivatives by means of a single simulation, all flight regimes combined [20-24].

\footnotetext{
*PhD candidate, Dept of Weapon Systems and Ballistics of the Royal Military Academy, veronique.debriey@dymasec.be.

$\dagger$ Master intern, Dept of Mechanical Engineeering of the Royal Military Academy.

$¥$ Associate Professor, Dept of Mechanical Engineeering of the Royal Military Academy. AIAA Member.

${ }^{\S}$ Professor, Dept of Weapon Systems and Ballistics of the Royal Military Academy.
} 
This paper will use an uncoupled method to determine the coefficients of interest with focus on very low subsonic regimes, for specific types of fin-stabilized applications, like non-lethal projectiles or short-range mortars. Indeed, the absence of shocks does not imply the absence of complexity in terms of numerical solution and viscous flow since laminar to turbulent transition and flow induced as well as wall induced separation occur in the boundary layer. Experimental data will be collected in parallel to consolidate the aerodynamic predictions.

\section{Methodology}

\section{A. Computational Approach}

A first CFD methodology validation will be done starting from available results on a $83 \mathrm{~mm}$ caliber body-fin configuration at Mach 0.65 for a moderate range of angles of attack [25]. The different static coefficients (drag, lift and pitch) will be compared using steady RANS-simulation with two different low-order turbulence models including transition (k-ke- and SST k- and ) [26-31]. A methodology to capture the pitch-damping coefficient will also be presented in order to check if the desired terminal position at the target can be guaranteed in the development phase of ulterior finned-stabilized projectiles.

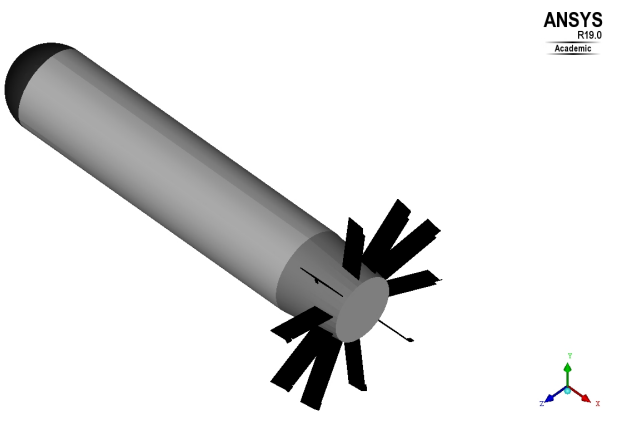

Fig. $183 \mathrm{~mm}$ body-fin configuration.

The main part of the study will focus on very low subsonic velocities, between 0.1 Mach and 0.4 Mach, to analyze more deeply the viscous effect on the profiles. A typical non-lethal fin-stabilized 12-gauge geometry will be used, with and without a fin cant angle of 10 degrees. In those configurations, the body of the projectile is wider than the wingspan, which necessarily influences the role of the fins. Again, the static coefficients will be calculated with the method used above as well as the dynamic stability by means of the pitch-damping coefficient. Detailed investigations will be conducted to assess modeling sensitivities (including a grid sensitivity study) [32] and limitations at low velocity regarding the numerical and aerodynamic parameters.

The mesh used for the steady and unsteady RANS simulations of the full projectile in free-air consists typically of 2 million elements with a prismatic boundary layer mesh comprising 10 layers resulting in an average value for $y+$ of one
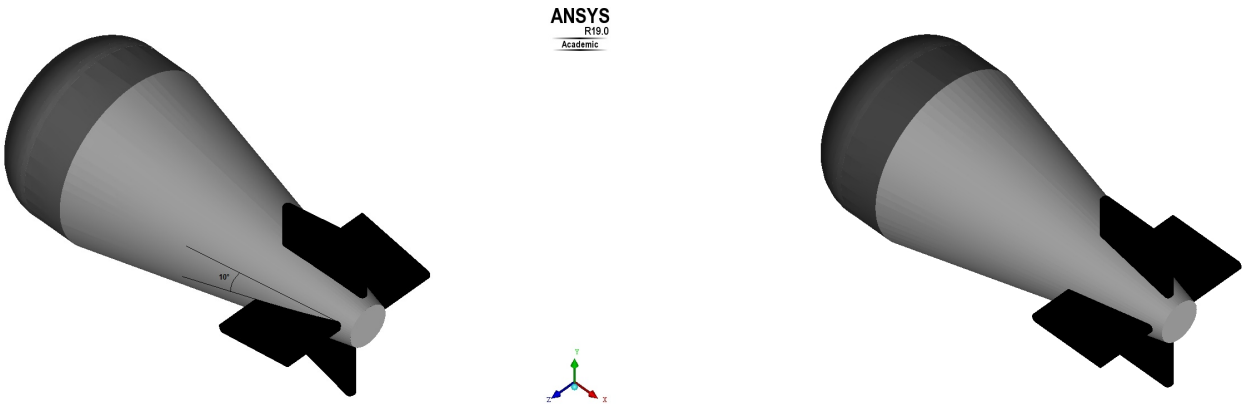

Fig. 2 12-GAUGE finned projectile with and without a $10^{\circ}$ cant angle. 
along the adiabatic no-slip walls. The domain extends to 20 projectile-lengths where pressure-far-field conditions are applied together with the desired angle of attack.

Also, advantage will be taken of the boundary layer analysis at different angles of attack to advise some parametric considerations for the geometry of such projectiles in order to improve their flight (cone angle, fin length and position, ...).

\section{B. Experimental Approach}

By means of an aerodynamic force balance, the three static coefficients (drag, lift and pitch) will be measured for the axisymmetric configuration in a low turbulence wind tunnel going up to 0.1 Mach. In a parallel way, two different visualizations of the boundary layer will be made in order to validate the CFD predictions. In the first one, an infrared thermography [33, 34] will be used to assess the state of the boundary layer. In the second one, the projectile will be coated with a proprietary oils and pigments mixture for surface flow visualizations. Since it is impossible to increase the Mach number in the wind tunnel, the effect of the Reynolds number will be observed by adapting the dimensions of the projectile.

\section{Effectiveness Analysis}

At the end of this study, the parametric considerations of section II.A. will be used to develop different improved geometries of projectiles that will be fired at ranges up to $100 \mathrm{~m}$. An appropriate 6-DOF model will be implemented with the different coefficients discussed above as inputs, to evaluate the variations in terms of computed trajectories. The purpose of this step is to highlight the advantages and limitations of the Point Mass Model, in comparison with a more complete model who considers the attitude of the projectile.

\section{Preliminary Results}

Simulations on the $83 \mathrm{~mm}$ caliber body-fin configuration at 0.65 Mach [25] with a 3 equation SST k- and $\gamma$ model were already performed with ANSYS Fluent R19.0. Good agreement for angles of attack smaller than 5 degrees were founded. At higher angles of attack, the results are less accurate and request a more detailed analysis of the boundary layer, with the idea of refining the mesh in some critical places where cross-flow becomes significant and optimize the model parameters to yield a better modeling of the complex viscous effects.
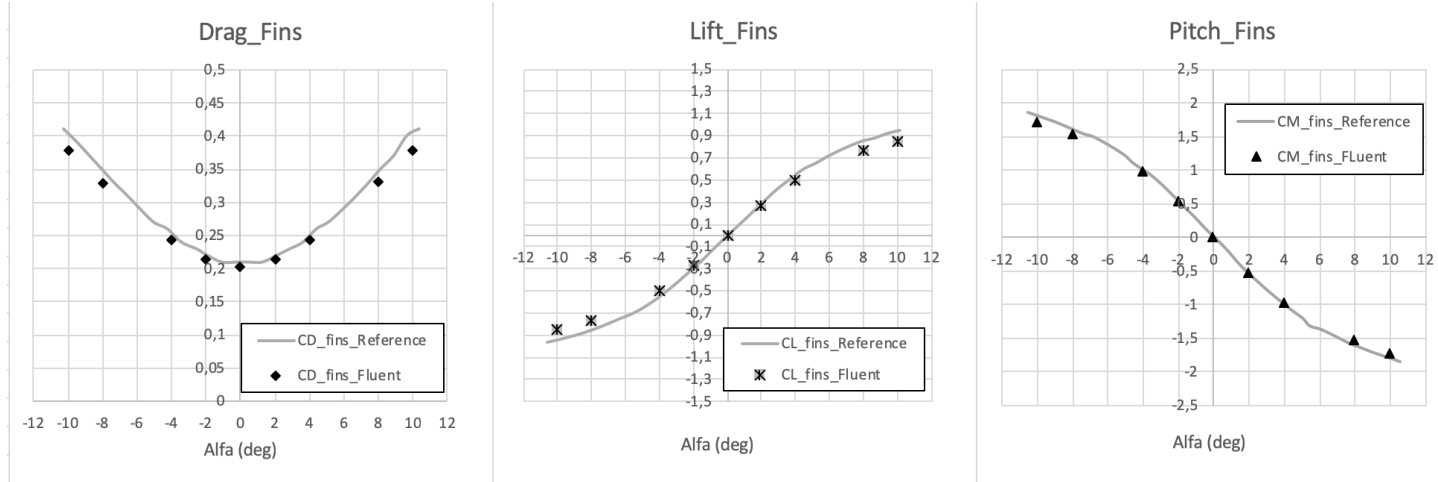

Fig. 3 First results showing the drag, lift and pitch coefficients for the fins in function of the angle of attack. 


\section{References}

[1] Mc Coy, R. L., "Modern Exterior Ballistics,” 1999, Schiffer Publishing Ltd. : Atglen, PA.

[2] Morrison, A. M., and Ingram, C. W., "Stability coefficients of a missile at angles of attack," Journal of Spacecraft and Rockets, Vol. 13, No. 5, 1976, pp. 318-319. doi:10.2514/3.27910.

[3] Weinacht, P., "Projectile Performance, Stability, and Free-Flight Motion Prediction Using Computational Fluid Dynamics," Journal of Spacecraft and Rockets, Vol. 41, No. 2, 2004, pp. 257-263. doi:10.2514/1.1037.

[4] Cayzac, R., Carette, E., Champigny, P., Thépot, R., and Donneaud, O., "Analysis of static and dynamic stability of spinning projectiles,” 21st International Symposium on Ballistics, 2004, pp. 66-73.

[5] DeSpirito, J., Silton, S., and Weinacht, P., "Navier-Stokes Predictions of Dynamic Stability Derivatives: Evaluation of Steady-State Methods," Journal of Spacecraft and Rockets, 2009. doi:10.2514/1.38666.

[6] Silton, S., and Howell, B., "Predicting the Dynamic Stability of Small-Caliber Ammunition," 25th International Symposium on Ballistics, 2011.

[7] Bhagwandin, V. A., and Sahu, J., "Numerical Prediction of Pitch Damping Stability Derivatives for Finned Projectiles," 2013, p. 52. doi:10.2514/1.A32734.

[8] Sturek, W. B., Nietubicz, C. J., Sahu, J., and Weinacht, P., "Applications of computational fluid dynamics to the aerodynamics of army projectiles," Journal of Spacecraft and Rockets, Vol. 31, No. 2, 1994, pp. 186-199. doi:10.2514/3.26422.

[9] Sahu, J., “Time-Accurate Numerical Prediction of Free Flight Aerodynamic of a Finned Projectile,” 2006. doi:10.1109/HPCMPUGC.2006.72.

[10] Silton, S., "Navier-Stokes Computations for a Spinning Projectile From Subsonic to Supersonic Speeds," Journal of Spacecraft and Rockets, Vol. 42, No. 2, 2005, pp. 223-231. doi:10.2514/1.4175.

[11] Cayzac, R., Carette, E., Thépot, R., and Champigny, P., "Recent Computations and validations of projectile unsteady aerodynamics," 22nd International Symposium on Ballistics, 2005, pp. 2-9.

[12] Sahu, J., "Numerical Computations of Unsteady Aerodynamics of Projectiles using an Unstructured Technique," Computational Fluid Dynamics, 2006, pp. 886-893. doi:21005-5066.

[13] Silton, S., "Navier-Stokes Predictions of Aerodynamic Coefficients and Dynamic Derivatives of a 0.50-cal Projectile," 29th AIAA Applied Aerodynamics Conference, American Institute of Aeronautics and Astronautics, Honolulu, Hawaii, 2011. doi:10.2514/6.2011-3030.

[14] Lesage, F., "Navier-Stokes Prediction of Pitch Damping Coefficients for Projectiles," Centre de Recherche pour la Défense Valcartier, 1997.

[15] Oktay, E., and Akay, H., "CFD predictions of dynamic derivatives for missiles," 40th AIAA Aerospace Sciences Meeting \& Exhibit, 2002. doi:10.2514/6.2002-276.

[16] Park, S. H., Kim, Y., and Kwon, J. H., "Prediction of Damping Coefficients Using the Unsteady Euler Equations," Journal of Spacecraft and Rockets, Vol. 40, No. 3, 2003, pp. 356-362. doi:10.2514/2.3970.

[17] Despirito, J., and Heavey, K., "CFD Computation of Magnus Moment and Roll Damping Moment of a Spinning Projectile," AIAA Atmospheric Flight Mechanics Conference and Exhibit, 2006. doi:10.2514/6.2004-4713.

[18] Kokes, J., Costello, M., and Sahu, J., "Generating an aerodynamic model for projectile flight simulation using unsteady time accurate computational fluid dynamic results," WIT Transactions on Modelling and Simulation, 2007. doi:10.2495/CBAL070041.

[19] Sahu, J., "Numerical Computations of Dynamic Pitch-Damping Derivatives using Time-Accurate CFD Techniques," International Symposium on Ballistics, 2008.

[20] Sahu, J., “Advanced Time-accurate CFD/RBD Simulations of projectiles in free flight,” DODUGC, Vol. 1, 2005 , pp. 86-91. doi:10.1109/DODUGC.2005.7.

[21] Weinacht, P., "Virtual wind tunnel Experiments for Small Caliber Ammunition Aerodynamic Characterization," , 2007. doi:MD21005-5066. 
[22] Montalvo, C., and Costello, M., "Estimation of Projectile Aerodynamic Coefficients Using Coupled CFD/RBD Simulation Results," AIAA Atmospheric Flight Mechanics Conference, 2010. doi:10.2514/6.2010-8249.

[23] Sahu, J., "Virtual Fly-Out Simulations of a spinning Projectile from Subsonic to Supersonic Speeds," 29th AIAA Atmospheric Flight Mechanics Conference, 2011. doi:10.2514/6.2011-3026.

[24] Sahu, J., Costello, M., and Montalvo, C., "Development and Application of Multidisciplinary Coupled Computational Techniques for Projectile Aerodynamics," 7th International Conference on Computational Fluid Dynamics, 2012. doi:ICCFD7-4504.

[25] Silton, S. I., "Quasi-Steady Simulations for the Efficient Generation of Static Aerodynamic Coefficients at Subsonic Velocities," 35th AIAA Applied Aerodynamics Conference, , No. June, 2017, pp. 1-16. doi:10.2514/6.2017-3398.

[26] Walters, D., and Cokljat, D., "A three-equation eddy-viscosity model for Reynolds-averaged Navier-Stokes simulations of transitional flows," Journal of Fluids Engineering, Vol. 130, No. 12, December2008, pp. 121-401.

[27] Menter, F., "Two-Equation Eddy-Viscosity Turbulence Models for Engineering Applications," AIAA Journal, Vol. 32, No. 8, August 1994, pp. 1598-1605.

[28] Menter, F., Langtry, R., Likki, S., Suzen, Y., Huang, P., and Volker, S., “A correlation-Based Transition Model Using Local Variables: Part I Model Formulation,” Turbo Expo 2004, Vol. 4, 2004. doi:ASME-GT2004-53452.

[29] Langtry, R., and Menter, F., "Transition Modeling for general CFD applications in aeronautics," 43rd AIAA Aerospace Sciences Meeting and Exhibit, January 10-13 2005. doi:AIAA2005-522.

[30] Langtry, R., and Menter, F., "Correlation-Based Transition Modeling for Unstructured Parallelized Computational Fluid Dynamics Codes,” AIAA Journal, Vol. 47, No. 12, December 2009, pp. 2894-2906.

[31] Arnal, H. M., D., and Coustols, E., "Théorie de l'instabilité laminaire et critères de transition en écoulement bi et tridimensionnel," AIAA Journal, Vol. 2, 1984, pp. 125-143.

[32] Celik, I., Ghia, U., ROACHE, P., Freitas, C., H., C., and P.E., R., "Procedure for estimation and reporting of uncertainty due to discretization in CFD Applications," Journal of Fluids Engineering, Vol. 7, No. 130, July 2008, pp. 1-4.

[33] Joseph, L., Borgoltz, A., and Devenport, W., "Infrared thermography for detection of laminar-turbulent transition in lowspeed wind tunnel testing," Experiments in Fluids, 2016. doi:10.1007/s00348-016-2162-4.

[34] Simon, B., Filius, A., Tropea, C., and Grundmann, S., "Infrared thermography for dynamic detection of laminar-turbulent transition," Experiments in Fluids, 2016. doi:10.1007/s00348-014-2178-9. 